\title{
Innovations
}

\section{Stress and working with addicts: a role for meditation?}

\author{
R. FARMer, Consultant and Honorary Senior Lecturer in Psychiatry, Drug Dependency \\ Clinic, National Temperance Hospital, University College Hospital, \\ 122 Hampstead Road, London NW1 2LT; and Rosalind RAMSAY, Senior Registrar \\ in Psychiatry, Portnalls Unit, Farnborough Hospital, Orpington, Kent BR6 8ND
}

Occupational stress is frequent among individuals whose work brings them into close contact with other people. One putative means of preventing or alleviating such stress is meditation (West, 1987). A six week course in meditation was recently held for staff in the Drug Dependence Service based at University College Hospital, London. The idea for the course came from the head of the unit who had personal experience of meditation. The course and its acceptability to staff are described below.

\section{The study}

All members of staff at the Drug Dependency Unit (DDU) and the associated Health Improvement Team (HIT) were informed of the course and invited to attend. The group met for an hour at 4 p.m. on six consecutive Tuesdays. It was led by a professional meditation teacher who is affiliated to a local Buddhist centre. Although the meditation teacher is a practising Buddhist, and the two types of meditation taught are in the Buddhist tradition, no adherence to this belief system is necessary to use the techniques in question and they are not thought to compromise other religious beliefs. In the first three weeks, staff were introduced to 'mindfulness of breathing', and in the following three sessions they learnt 'metta bhavana'.

The former is said to lead to calmness and greater awareness (Thera, 1962) while the latter aims to develop positive feelings about oneself and other living beings. It was intended that the course would be suitable for those who had no previous experience of meditation as well as those who had meditated before. Sessions built on work done earlier in the course but attendance at previous sessions was not required in order to participate.

The first session included a general introduction to 'What is meditation?' and 'How can it help us?' Each of the following five sessions began with time to report back and in the sixth session there was an opportunity to discuss future plans and establishing regular practice.
Two weeks after the course ended a 15 item questionnaire was given to all members of staff in the DDU and HIT to evaluate their response to the meditation course. Non-attenders were also asked to complete the questionnaire. The questionnaires were unsigned.

\section{Findings}

Of the 22 members of the DDU and HIT staff, 16 completed and returned questionnaires, giving a response rate of $73 \%$. Thirteen subjects attended one or more sessions while the three who had not come to any reported regular commitments outside the unit on a Tuesday afternoon.

A mean of 2.9 sessions were attended by the remaining 13 . Of the thirteen attenders, six went to sessions on mindfulness of breathing only (mean attendance, 1.7 sessions). The other seven tried both kinds of meditation (mean overall attendance 4.9, mean of 2.7 mindfulness of breathing sessions, 1.6 metta bhavana sessions). No subject first joined the group for the later three metta bhavana sessions.

Six of the 16 responders claimed prior theoretical knowledge of meditation and four had previous experience of it. Responses from all attenders were generally favourable, describing sessions as, for example, "wonderfully relaxing", "an oasis of pleasure", and "enlightening". Another subject appreciated "the requirement to make time for myself", as well as considering the course "a good team building exercise". Those who came to fewer sessions felt less able to comment on the benefits of meditating due to their limited attendance. There were also critical comments about the time being "too late in the day". (On Tuesdays, staff work from 9 a.m. until 7 p.m. in order to run a weekly evening clinic). When meditation ended at 5 p.m. one subject reported being "not ready to continue working".

However, six subjects continued to meditate between sessions or after the course finished; six also expressed interest in continuing elsewhere while a seventh had "thought about it with no conclusion". 
Responses of all attenders to the question, "What did you expect our course to be like?", were very similar, for example, "I thought the idea sounded good and I was willing to give it a try". One subject who said she was a practising Christian expressed anxiety as she "had been warned against some Eastern types of meditation which involved emptying the mind". In reply to "How did you decide whether or not to come to any of the course?", many responders indicated that although they had wanted to attend more of it, they felt clinical commitments interfered with their doing so.

Of the 13 attenders, 12 thought "this kind of approach has a place for staff in the unit". The 13th had previously stated her doubt about the value of meditation on religious grounds. Of the three nonattenders, two definitely thought meditation would be useful for staff and the third that it might be. In general, subjects recognised their need to have "time out in a calm and relaxed atmosphere without client discussion", believing this would "help to alleviate stress", and "create a good atmosphere in the staff team".

Subjects were, however, undecided about the usefulness of meditation for patients, nine believing it had a role, but five expressing some reservations about its use, commenting, for example, "Getting them to attend in the first place may be difficult" or "Is the DDU the right place to hold such a group?".

\section{Comment}

Staff at the drug dependency service indicated the value they see in having a regular meeting not involving administrative matters or client discussion. They also expressed a positive attitude to trying meditation, believing it was likely to lead to better functioning of the unit. Six members of staff had previous knowledge of meditation and four had already discovered some benefit from meditating for themselves.

At the same time, staff experienced guilt over taking out time from clinical duties to attend the course. This conflict between perceived 'own' needs and 'patient' needs affected continuing attendance on the course, so that staff members who appeared more overwhelmed by patient demands felt less able to spend one hour a week away from clinical duties at work and were more likely to stop attending.

This accords with previous findings that it is the most dedicated, committed, enthusiastic and idealistic staff who are consistently found to be at risk of burnout (Freudenberger, 1975; Meier, 1983).

At the end of the course there was a positive response to the proposal of further regular meditation within the unit. Indeed, six staff were continuing to meditate on their own, including two without previous experience of it.

These data have several observable methodological limitations. The questionnaire was brief and unstandardised and the number of responses (16/22) not large. The study did not attempt formal assessment of levels of stress although responders gave clear descriptions of feeling under pressure at work. A prospective study including baseline and on-going measures of stress would give a clearer indication of the possible value of meditation. It would also be interesting to explore the use of meditation among other staff groups and to compare it with other methods of reducing stress such as exercise.

Meditation requires continuing practice but is an immediately accessible technique to aid relaxation that an individual can learn over several sessions in a group setting. Given the adverse effects of burnout on staff performance, meditation may be a relatively cheap way to improve wellbeing and hence performance of individuals and a service.

\section{References}

FreUdenberger, H. J. (1975) The staff burnout syndrome in alternative institutions. Psychotherapy: Theory, Research and Practice, 12, 73-82.

MEIER, S. T. (1983) Towards a theory of burnout. Human Relations, 36, 899-910.

THERA, N. (1962) The Heart of Buddhist Meditation: A Handbook of Mental Training Based on the Buddhist Way of Mindfulness. London: Rider.

West, M. A. (ed). (1987) The Psychology of Meditation. Oxford: Clarendon Press. 